\title{
Day Times Microgram Per Milliliter Per Gram
}

National Cancer Institute

\section{Source}

National Cancer Institute. Day Times Microgram Per Milliliter Per Gram. NCI Thesaurus.

Code C112248.

Days times micrograms per milliliter, divided by grams. 